\title{
Astrovirus-Like, Coronavirus-Like, and Parvovirus-Like Particles Detected in the Diarrheal Stools of Beagle Pups
}

\author{
By \\ F. P. WTLLIAMs, JR. \\ Health Effects Research Laboratory, U.S. Environmental Protection Agency, \\ Cincinnati, Ohio, U.S.A. \\ With 5 Figures
}

Accepted May 26, 1980

\begin{abstract}
Summary
Astrovirus-like, coronavirus-like, and parvovirus-like particles were detected through electron microscopic (EM) examination of loose and diarrheal stools from a litter of beagle pups. Banding patterns obtained from equilibrium centrifugations in $\mathrm{CsCl}$ supported the EM identification. Densities associated with the identified particles were: $1.34 \mathrm{~g} / \mathrm{ml}$ for astrovirus, $1.39 \mathrm{~g} / \mathrm{ml}$ for "full" parvovirus, and $1.24-1.26 \mathrm{~g} / \mathrm{ml}$ for "typical" coronavirus. Convalescent sera from the pups aggregated these three particle types as observed by immunoelectron microscopy (IEM). Only coronavirus-like particles were later detected in formed stools from these same pups. Coronavirus and parvo-like viruses are recognized agents of canine viral enteritis, however, astrovirus has not been previously reported in dogs.
\end{abstract}

\section{Introduction}

A number of virus-like particles detected in fecal material by electron microscopy (EM) have been found to manifest sufficiently distinct morphology to warrant individual classification. Such readily identified agents include: rotavirus (11), coronavirus (30), adenovirus (12), calicivirus (20), and possibly minireo/rotavirus $(23,29)$.

Astrovirus, another characteristic agent identified by EM, was originally associated with infantile gastroenteritis $(18,19)$. Subsequent investigations confirmed the identification of this agent in stools of newborns with acute nonbacterial gastroenteritis (16), and in outbreaks of gastroenteritis involving children and adults $(2,15)$. Virus-like particles, $28-30 \mathrm{~nm}$ in diameter, possessing the distinctive star-like surface morphology have also been detected in the diarrheal feces of lambs (27) and calves (32).

This paper reports the detection of astrovirus-like particles in loose and diarrheal stools encountered in a litter of seven beagle pups obtained for laboratory research 
purposes. Other particle-types previously associated with canine viral enteritis, coronavirus (5) and parvovirus $(6,10)$, were also detected.

\section{Materials and Methods}

A litter of seven $11 \frac{1}{2}$-week-old pups, cesarean section delivered and kept in a germ-free environment, was acquired after detection of bacteria in the isolation unit. Upon arrival the pups appeared in good condition, however, within 3 to 4 days loose stools were noted. Two pups appeared severely ill 7 and 10 days after arrival and were sacrificed for necropsy by associated medical (laboratory animal) personnel. Symptoms included diarrhea (with some blood noted), excessive salivation, and convulsions.

A stool specimen for EM examination was collected from each of the remaining five pups two weeks after arrival. All of the stools were either loose or diarrheal and included a specimen from a third severely-affected pup (a saliva specimen was also obtained from this pup). Twelve days later, all pups appeared in good condition and were excreting formed stools. At that time, a second stool specimen was collected from four of the pups (one mildly-affected pup had been used in an unrelated experiment and was not available).

Five weeks after arrival, blood specimens $(5-10 \mathrm{ml})$ were drawn from all five pups; and the individual sera were obtained after being centrifuged free of cellular and clotted material at $800 \times g$ for 30 minutes.

\section{Stoal Preparation}

A 20 percent suspension $(30 \mathrm{ml})$ of each stool specimen was made in distilled water. Large particulate material was removed by initial centrifugation at $170 \times g$ for $15 \mathrm{~min}$ utes. The supernatant was further centrifuged at $3500 \times g$ for 30 minutes, removing additional material. The supematant was finally centrifuged at $110,000 \times g$ for 2 hours using a Beckman $60 \mathrm{Ti}$ rotor. The resulting high-speed pellet was resuspended with $\approx$ small volume of water and examined with the electron microseope.

\section{Electron Microscopy (EM)}

A drop of sample to be examined was placed on a copper EM grid (carbon substrate), allowed to stand one minute, and the excess removed with a piece of filter paper. The grid was rinsed with 1 or 2 drops of distilled water followed by negative staining with 2 percent phosphotungstic acid, $\mathrm{pH} 7$. After the excess stain was removed and the grid dried, the preparation was examined at $80 \mathrm{Kv}$ on a JEOL $100 \mathrm{CX}$ electron microscope.

\section{CsCl Equitibrium Centrifugation}

After EM examination, portions of each loose or diarrheal stool preparation were combined (excluding one preparation found to contain parvovirus-like particles and separately centrifuged) and suspended in a solution of CsCl (in PBS, pH 7.3) with a refractive index of 1.370. The suspension was placed in a centrifuge tube and centrifuged at $110,000 \times g$ for 24 hours (Beckman SW 41 Ti rotor). Fractions of $0.5 \mathrm{ml}$ were collected from the bottom of the tube. The refractive index and the absorbance at $260 \mathrm{~nm}$ of each fraction was measured. The density of each fraction was calculated using the

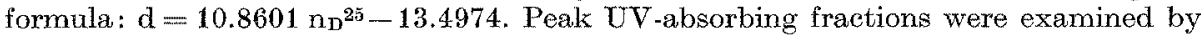
EM. All fractions were tested for hemagglutinating capacity using rhesus RBC's.

The parvovirus-like particle preparation was similarly centrifuged, fractionated, and examined. Centrifuge time was extended to 48 hours to optimize the development of the banding pattern.

Material remaining at the top of both gradients was found to contain "typical" coronavirus-like particles. These top components were combined, suspended in a CsCl/ PBS solution with a refractive index of 1.355 , and centrifuged for 48 hours. Fractions were collected and processed as previously described. 
Immunoelectron Microscopy (IEM)

Two syringe drops (approximately $0.025 \mathrm{ml}$ ) of unaggregated suspensions of each particle-type were incubated $\left(4^{\circ} \mathrm{C}\right.$ overnight) with $1: 10$ dilutions $(0.1 \mathrm{ml}$ volumes in PBS) of convalescent sera obtained from each of the pups. The incubated suspensions were then examined by EM for the appearance of aggregated particles. Serum incubations involving the "typical" coronavirus-like particle were examined after one hour as increased antibody attachment to the particles obscured their characteristic fringe projestions.

\section{Cell Culture}

Cesium chloride banded particle suspensions as well as high-speed pellet resuspensions were inoculated onto cultures of primary canine kidney, primary human embryo kidney, and Madin Darby canine kidney cells. Inoculated cultures were examined daily for cytopathic effect (CPE). Supernatants of all cultures exhibiting possible CPE were examined by EM for the presence of virus-like particles.

\section{Results}

\section{Electron Microscopy (EM)}

Examination of the loose and diarrheal stool preparations revealed a roughly spherical virus-like particle being shed by each of the pups. A definite star shape was observed on the surface of a portion of these particles (Fig. 1a). The diameter of the particles was slightly larger than that of cell culture propagated poliovirus when observed at the same magnification settings. The mean diameter of 100 particles $( \pm S D)$ was $28.4 \pm 1.0 \mathrm{~nm}$. Indistinct structures could be observed at times surrounding the particles. The observed particle characteristics eorrelated with those initially described for the astrovirus particle $(18,19)$ and as no hollow centers were observed within the star shapes, the particles could not be confused with calicivirus (21).

A smaller particle-type was found to predominate in the stool obtained from the more severely-affected pup (Fig. 1 b). No surface detail could be observed, however, certain stain penetrated-particles revealed a definite hexagonal shape (Fig. $1 \mathrm{~b}$, insert). The mean diameter of 100 particles was $22.7 \pm 0.5 \mathrm{~nm}$. As the relatively small size was well within the range reported for the parvovirus group (3) and such hexagonal shapes reported for the canine parvovirus-like agents MVC (4) and CHEV (6), a similar parvovirus-like classification was suggested for this particle. Direct EM examination of the saliva specimen from this pup revealed the presence of the particle in antibody-like aggregates (Fig. 2a).

Two distinct types of particles resembling coronaviruses were also detected in the stool specimens. "Typical" coronavirus-like particles (Fig. 2 b, upper particle) had characteristic bulbous projections $(17,31)$ approximately $18 \mathrm{~nm}$ in length. The particles were detected in each of the stool specimens, although in no instance were they the predominant particle found. "Alternate" coronavirus-like particles (Fig. 2 b, lower particle and $2 \mathrm{c}$ ) had very thin to undetectable stalk-like projections which culminated in distal knobs or other indistinct shapes (total length, $21-29 \mathrm{~nm}$ ). Only two stool specimens were found to contain these particles. This "alternate" type resembled particles detected in human stools in India (22) and has since been reported more characteristic of coronaviruses detosted in. human stools $(7,8)$. Both coronavirus-like particle-types were pleomorphic with 
average diameters (excluding projections) generally ranging from $50-125 \mathrm{~nm}$. Particles in excess of $550 \mathrm{~nm}$ in a single dimension were occasionally seen.

The particle-types detected in the acute phase stools from each of the pups is presented in Table 1. No specimens were obtained from the sacrificed dogs. Only the "alternate" coronavirus-like particles (from pups Nos. 3 and 4) remained readily detected in preparations of formed stools. Prolonged excretion of coronavirus has been noted (8) although the significance of such shedding remains unclear.

Table 1. Virus-like particles detected in loose and diarneal stools

\begin{tabular}{lllll}
\hline Pup & Astrovirus & Parvovirus & $\begin{array}{c}\text { Coronavirus } \\
\text { "typical" }\end{array}$ & $\begin{array}{l}\text { Coronavirus } \\
\text { "alternate" }\end{array}$ \\
\hline 1 & + & - & + & - \\
2 & + & + & + & - \\
3 & + & - & + & + \\
4 & + & - & + & + \\
5 & + & - & + & - \\
\hline
\end{tabular}

\section{CsCl Equilibrium Centrifugation}

Cesium chloride equilibrium centrifugation of the combined stool preparations (excluding the parvovirus-like particle preparation) yielded two distinct bands of $260 \mathrm{~nm}$ absorbing material (Fig. 3 a) with measured peaks at densities of 1.41 and $1.34 \mathrm{~g} / \mathrm{ml}$. Examination by EM revealed "alternate" coronavirus-like particles at $1.41 \mathrm{~g} / \mathrm{ml}$ and astrovirus-like particles at $1.34 \mathrm{~g} / \mathrm{ml}$.

Centrifugation of the parvovirus-like particle preparation resulted in three distinct UV-absorbing bands (Fig. $3 \mathrm{~b}$ ) with measured peaks at $1.39,1.34$, and $1.30 \mathrm{~g} / \mathrm{ml}$. Exclusively "full" (stain unpenetrated) parvovirus-like particles were found by EM at $1.39 \mathrm{~g} / \mathrm{ml}$. Astrovirus-like particles were again found at $1.34 \mathrm{~g} / \mathrm{ml}$ and "empty" (stain penetrated) parvovirus-like parbicles were found at $1.30 \mathrm{~g} / \mathrm{ml}$. Fractions at the bottom of the tube were observed to contain debris.

Visible material remaining at the top of the gradients was found to contain "typical" coronavirus-like particles among various membranous elements. Subsequent centrifugation of this material in a less dense $\mathrm{CsCl}$ solution did not result in a spectrophotometrically detected band. Examination by EM did detect peak numbers of these particles at densities of $1.24-1.26 \mathrm{~g} / \mathrm{ml}$.

Each of the CsCl-banded particle-types is shown in Fig. 4 (a-e). The capacity to agglutinate rhesus RBC's was found only in CsCl fractions containing either "full" or "empty" parrovirus-like particles.

Fig. 1. Electron micrographs of two stool preparations ( $\mathrm{Bar}=100 \mathrm{~nm}$ ). a Astroviruslike particles found in all loose and diarrheal stools. Star shapes can be seen on arrowed particles. Insert shows an enlarged partiele possessing a 6-pointed star morphology. $b$ Astrovirus-like particles (A) and the more predominant parvovirus-like particles $(P)$ found in the stool of a more severely-affected pup. Insert shows the hexagonal shape of a stain penetrated particle ( $\mathrm{Bar}=50 \mathrm{~nm}$ for both inserts) 

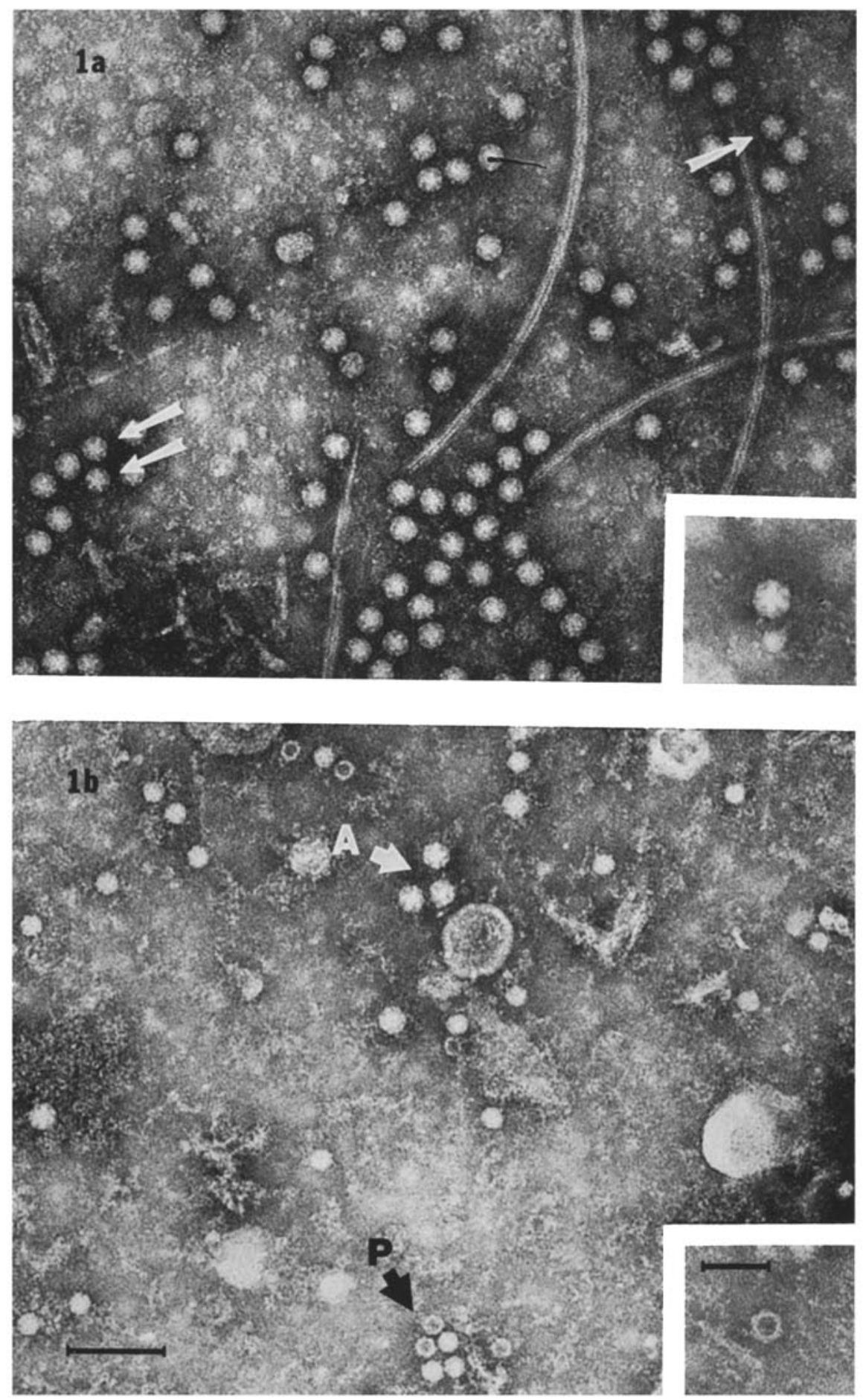

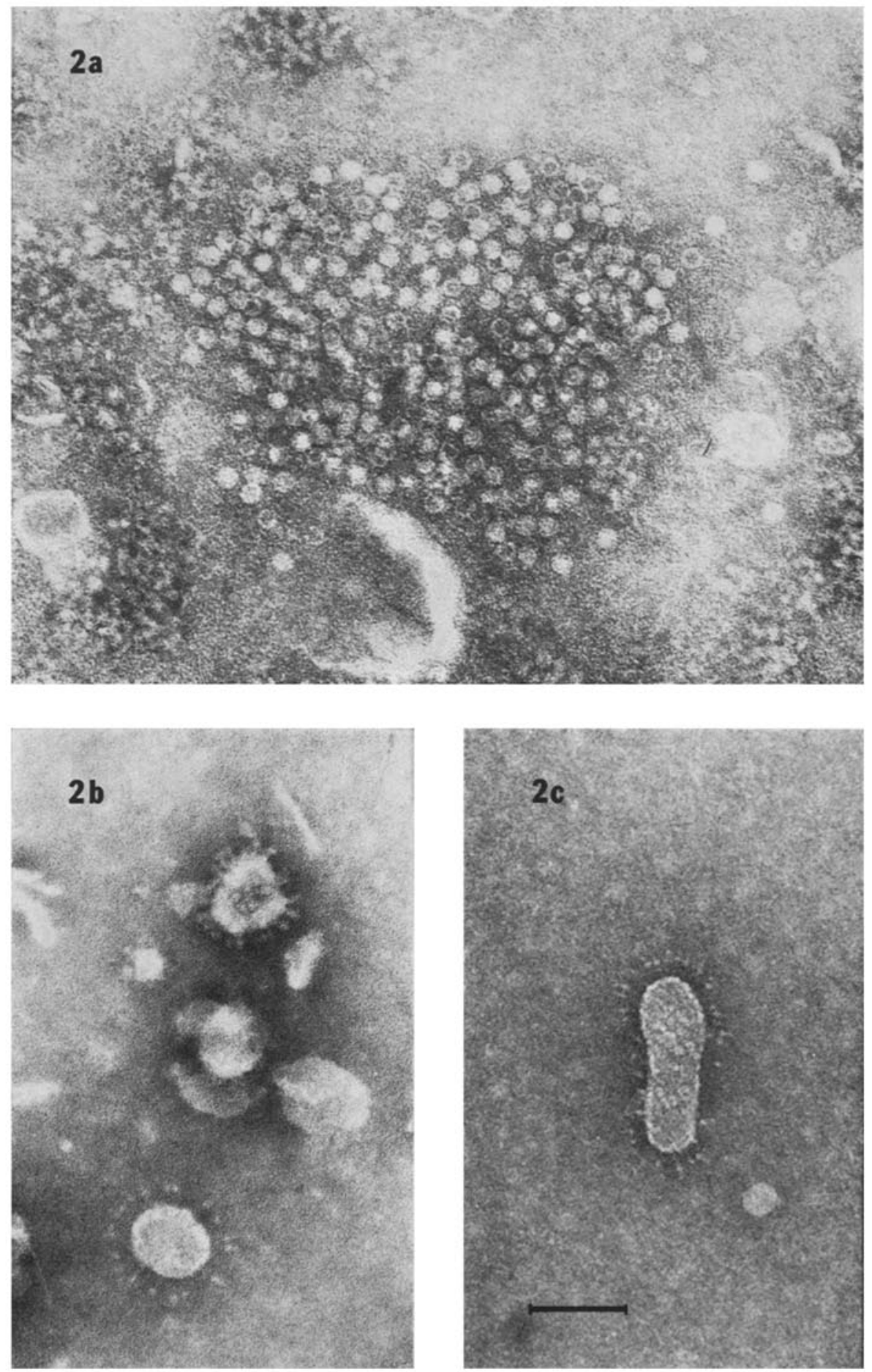


\section{Immunoelectron Microscopy (IEM)}

Convalescent sera obtained from each of the pups aggregated astrovirus-like, parvovirus-like, and "typical" coronavirus-like particles (Table 2). The aggregates are shown in Fig. $5(\mathrm{a}-\mathrm{c})$. "Alternate" coronavirus-like particles (Fig. 5d) were not aggregated by any of the sera.

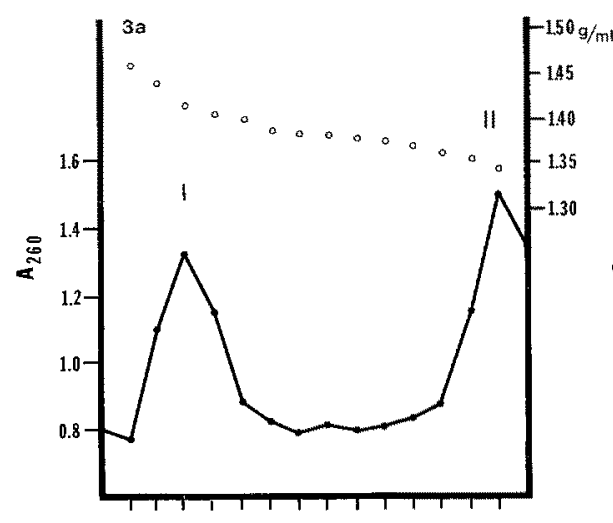

FRACTIONS

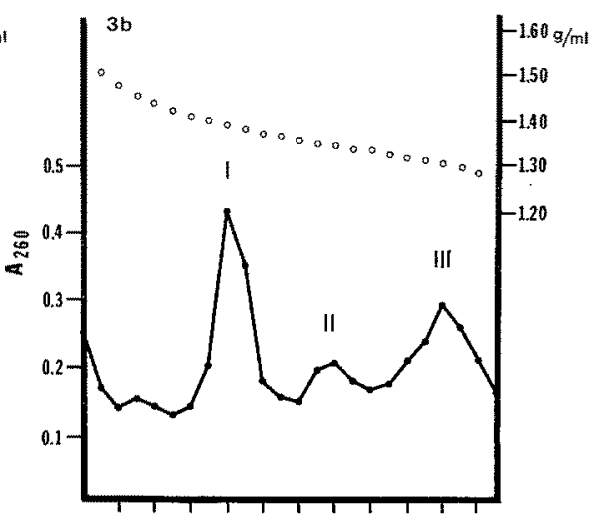

FRACTIONS

Fig. 3. $\mathrm{CsCl}$ equilibrium centrifugation of stool preparations. $a$ Combined stool preparations without parvovirus-like particles. Two $260 \mathrm{~nm}$ absorbing bands were detected with measured peaks at: I. $1.41 \mathrm{~g} / \mathrm{ml}$ ("alternate" coronavirus-like particles detected by EM). II. $1.34 \mathrm{~g} / \mathrm{m}$. (astrovirus-like particles). $b$ Stool preparation with parvoviruslike particles. Three bands were detected with peaks at: $I 1.39 \mathrm{~g} / \mathrm{ml}$ ("full" parvoviruslike particles). II $1.34 \mathrm{~g} / \mathrm{ml}$ (astrovirus-like particles). $I I I 1.30 \mathrm{~g} / \mathrm{ml}$ ("empty" parvovirus-like particles)

Table 2. Serum aggregation of virus-like particles detected in loose and diarrheal stools

\begin{tabular}{lllll}
\hline & & & Coronavirus & Coronavirus \\
Pup & Astrovirus & Parvovirus & "typical" & "alternate" \\
\hline 1 & + & + & + & - \\
2 & + & + & + & - \\
3 & + & + & + & - \\
4 & + & + & + & - \\
5 & + & + & + & - \\
\hline
\end{tabular}

\section{Cell Culture}

Particle associated CPE was not detected in any of the cell cultures. Premature deterioration of the cell monolayer (compared to control cultures) was noted in two inoculated primary canine kidney cultures, however, EM examination revealed no virus-like particles in the supernatants.

Fig. 2. Electron micrographs of parvovirus-like and coronavirus-like particles (Bar = $100 \mathrm{~nm}$ ). $a$ Saliva specimen from the more severely affected pup (Fig. 1b) showing parvovirus-like particles in an antibody-like aggregate. $b$ "Typical" (upper particle) and "alternate" (lower particle) forms of coronavirus-like particles seen in another stool preparation. o An "alternate" coronavirus-like particle with its lack of bulbous projections 


\section{Diseussion}

It was possible to identify astrovirus-like, coronavirus-like and parvovirus-like particles through EM examination of loose and diarrheal stools obtained from afflicted pups. The EM identification was supported by particle banding patterns established through equilibrium centrifugation in CsCl.

The density associated with the astrovirus-like particle, $1.34 \mathrm{~g} / \mathrm{ml}$, agrees with a previously reported value of $1.33-1.34 \mathrm{~g} / \mathrm{ml}$ for astrovirus detected in the stools of newborns with gastroenteritis (16).

Buoyant densities of "full" $(1.39 \mathrm{~g} / \mathrm{ml})$ and "empty" $(1.30 \mathrm{~g} / \mathrm{ml})$ parvoviruslike particles are in accordance with corresponding "mature virion" (1.39 to $1.42 \mathrm{~g} / \mathrm{ml})$ and "empty particle" $(1.31 \mathrm{~g} / \mathrm{ml})$ densities reported for the parvovirus group (3). A similar density of 1.4 was obtained for the cytopathogenic agent of the minute virus of canines (MVC) (26), while the reported densities associated with canine hemorrhagic enteritis virus (CHEV) were $1.43 \mathrm{~g} / \mathrm{ml}$ ("full"), $1.38 \mathrm{~g} / \mathrm{ml}$ ("full" and "empty") and $1.34 \mathrm{~g} / \mathrm{ml}$ ("empty") (6). Both these canine parvoviruslike agents agglutinated rhesus RBC's, as did the agent of this study.

The density associated with the "typical" coronavirus-like particle, 1.24 to $1.26 \mathrm{~g} / \mathrm{ml}$, conforms to a recently reported value of $1.245 \mathrm{~g} / \mathrm{ml}$ for a bovine coronavirus (13), while the value of $1.41 \mathrm{~g} / \mathrm{ml}$ associated with the "alternate" coronaviruslike particle may be indicative of a basically altered form. Treatment of HEV, a porcine coronavirus possessing typical bulbous projections, with dithiothreitol (DTT) has been shown to remove surface glycoproteins and to result in the appearance of thin, fibrous projections. This treatment also reduced infectivity (24). Such structural alteration resulting in the "alternate" coronavirus-like agent detected here may explain the failure of convalescent sera to react with it. Convalescent sera aggregation of the other particle types indicated general exposure of the pups to each of these agents.

The enteric pathogenesis of coronaviruses and parvovirus-like agents in dogs $(9,14)$, and astroviruses in lambs $(28)$ has been described. Each must be considered a possible etiologic agent of the diarrheal illness reported here. Three of the pups, however, appeared more severely affected than the others. The parvovirus-like particles were detected in the specimens obtained from one of these three pups. No specimens were available from the other two, as they had been sacrificed (necropsy reports obtained on the two pups noted bowel irritation). The association of the parvovirus-like particles with the severely-affected pup is consistent with the recently reported severe nature of outbreaks of parvovirus associated diarrheal disease (1). Detection of these particles in the saliva specimen supports the suspected existence of an alternative route of transmission not mediated by fecal exposure (25).

Fig. 4. Particle-types detected at different densities following $\mathrm{CsCl}$ equilibrium centrifugation (Bar $=100 \mathrm{~nm}$ ). a Astrovirus-like particles $(1.34 \mathrm{~g} / \mathrm{ml})$. b "Full" parvovirus-like particles $(1.39 \mathrm{~g} / \mathrm{ml})$. c "Empty" parvovirus-like particles $(1.30 \mathrm{~g} / \mathrm{ml})$. $d$ "Typical" coronavirus-like particles $(1.24-1.26 \mathrm{~g} / \mathrm{ml}) . e$ "Alternate" coronaviruslike particles $(1.41 \mathrm{~g} / \mathrm{ml})(\mathrm{Bar}=100 \mathrm{~nm})$ 

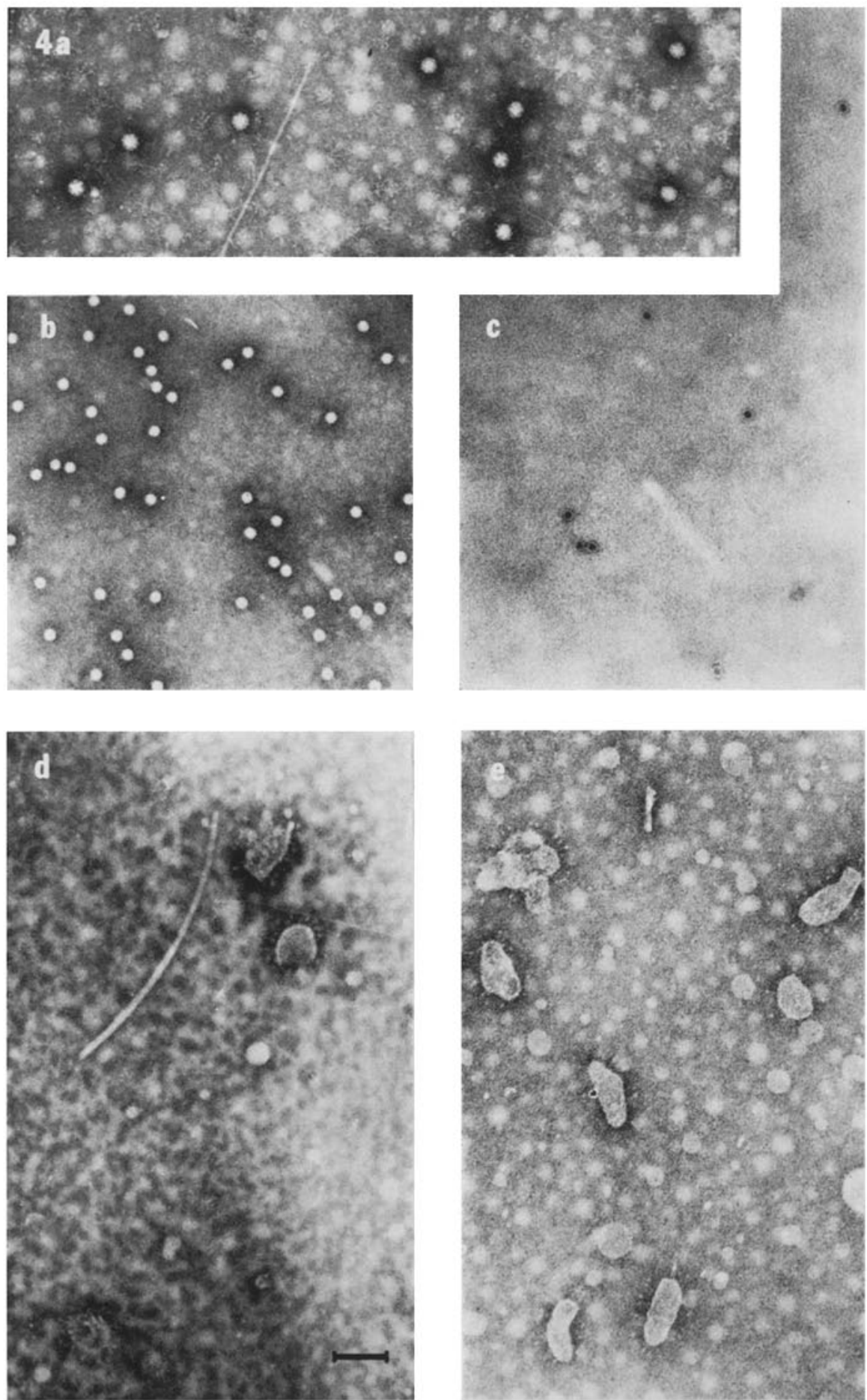

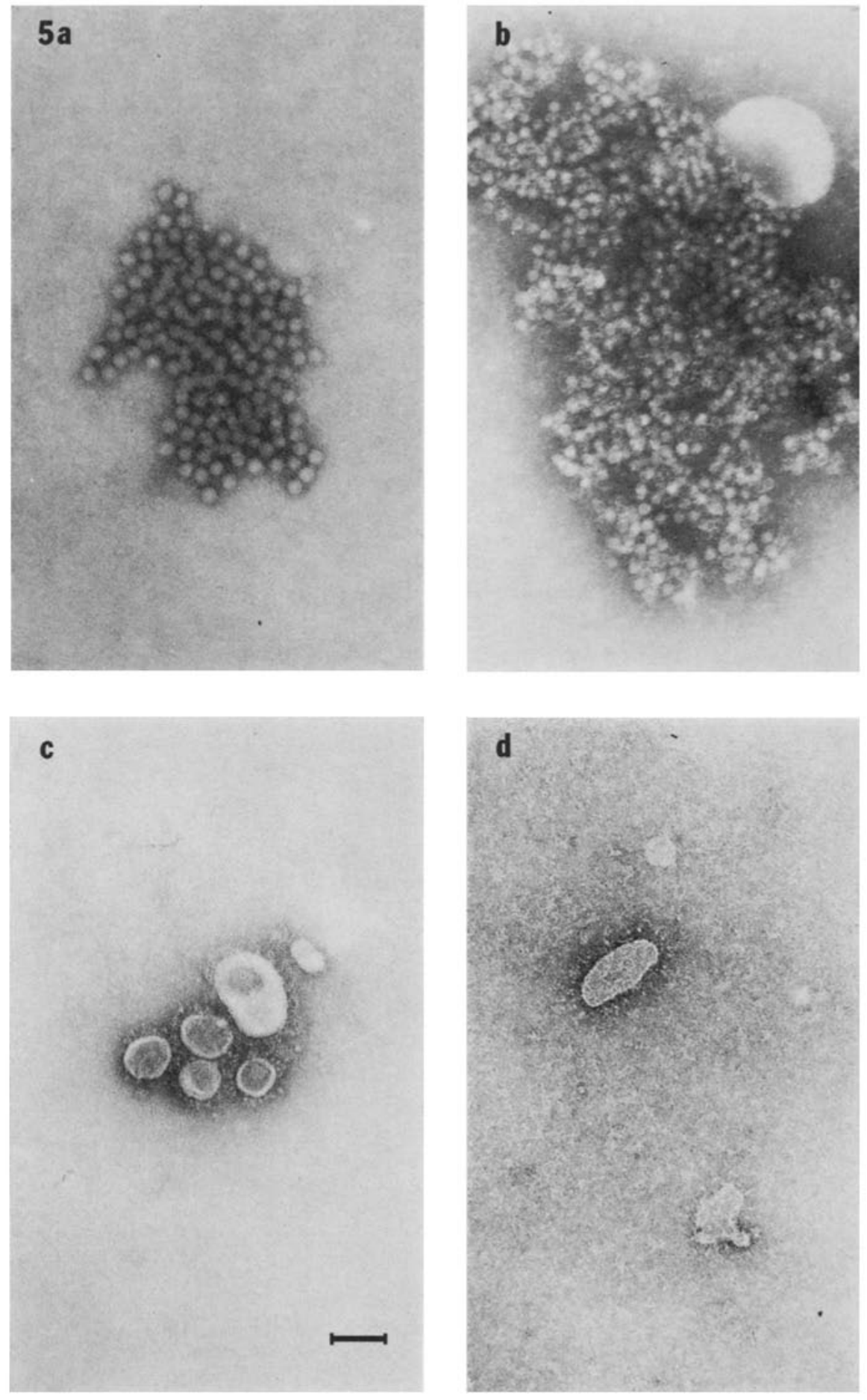
Although its role as an etiologic agent of the diarrheal illness encountered in this group of pups remains unclear, the detection of the astrovirus-like particles in the acute phase fecal specimens increases the number of species in which this agent has been found and associated with gastroenteritis.

The source of the illness has not been determined. Other dogs had recently been kept at the facility before the pup's arrival. Although no symptoms of illness were noted in the older dogs, asymptomatic shedding of each of these particletypes has been reported $(4,19,22)$. The previous isolation of the pups would maximize their susceptibility to such agents remaining in the environment.

Failure thus far to propagate any of these agents in cell culture has limited further investigation.

\section{References}

1. Appel, M. J. G., Cooper, B. J., Gremsen, H., Carmichatr, L. E.: Status report: canine viral enteritis. J. Amer. vet. med. Ass. 173, 1516-1518 (1978).

2. Ashlex, C. R., Caul, E. O., Paver, W. K.: Astrovirus-associated gastroenteritis in children. J. clin. Pathol. 31, 939-943 (1978).

3. Bachmann, P. A., Hoggan, M. D., Kurstak, E., Melmick, J. L., Pereira, H. G., Tattersall, P., Vago, C.: Parvoviridae: Second report. Intervirology 11, 248 to $254(1979)$.

4. Binn, L. N., Lazar, E. C., Eddy, G. A., KajnMa, M.: Recovery and characterization of a minute virus of canines. Infect. Immun. 1, 503-508 (1970).

5. Binn, L. N., Lazar, E. C., Kemenan, K. P., Huxsoli, D. L., Maromwiokx, R. H., STRANO, A. J.: Recovery and characterization of a coronavirus from military dogs with diarrhea. In: Proc. 78th Meeting, U.S. Animal Health Assoc,, Roanoke, Va., October 1974, 359-366. Richmond: U.S. Animal Health Assoc. 1975.

6. Burtonboy, G., Cotgnoul, F., Delferriere, N., Pastoret, P. P.: Canine hemorrhagic enteritis: detection of viral particles by electron microscopy. Arch. Virol. 61, 1-11 (1979).

7. Caul, E. O., Ashley, C. R., Egglestone, S. I.: Recognition of human enteric coronaviruses by electron microscopy. Med. Lab. Sci. 34, 259-263 (1977).

8. Caul, E. O., EgGlestone, S. T.: Further studies on human enteric coronaviruses. Arch. Virol. 54, 107-117 (1977).

9. Cooper, B. J., Carmichaex, L. E., Apred, M. J. G., Greisen, H.: Canine viral enteritis. II. Morphologic lesions in naturally occurring parvovirus infection. Cornell Vet. 69, 134-144 (1979).

10. Eugster, A. K., Bendele, R. A., Jones, L. P.: Parvovirus infection in dogs. J. Amer. vet. med. Ass. 173, 1340-1341 (1978).

11. Flewext, T. H., Bryden, A. S., Davies, H. A., Woode, G. N., Bridger, J, C., DerRICK, J. M.: Relation between viruses from acute gastroenteritis of children and newborn calves. Lancet ii, $61-63$ (1974).

12. Flewett, T. H., Bryden, A. S., Davies, H. A.: Diagnostic electron microscopy of faeces. I. The viral flora of the faeces as seen by electron microscopy. J. clin. Pathol. 27, 603-608 (1974).

13. HAJER, I., SToRz, J.: Structural polypeptides of the enteropathogenic bovine coronavirus strain LY-138. Arch. Virol. 59, 47-57 (1979).

Fig. 5. Convalescent serum aggregation of the particle-types (Bar $=100 \mathrm{~nm})$. a Astro" virus. b "Full" and "empty" parvovirus. c "Typical" coronavirus. $d$ "Alternate" coronavirus remained unaggregated 
14. Keeran, K. P., Jevis, H. R., Maronwtokr, R. H., Binn, L. N.: Intestinal infeetion of neonatal dogs with canine coronavirus 1-71: studies by virologic, histologic, histochemical and immunofluorescent techniques. Amer. J. vet. Res. 37, 247 to $256(1976)$.

15. Kurtz, J. B., Lee, T. W., Pickering, D.: Astrovirus associated gastroenteritis in a children's ward. J. clin. Pathol. 30, $948-952$ (1977).

16. MaAss, G., Baumeister, H. G., Hergemoller, R., Jansen, P., Schumadher, H.: Visualization by electronmicroscopy of $28 \mathrm{~nm}$ virusparticles (astroviruses) in faeces of newborns with acute nonbacterial gastroenteritis. Zbl. Bakt. Hyg., I. Abt. Orig. A 242, 423-430 (1978).

17. MoIntosh, K.: Coronaviruses: a comparative review. Curr. Top. Microbiol. Immunol. 63, 85-129 (1974).

18. Madeley, C. R., Cosgrove, B. P.: Viruses in infantile gastroenteritis. Lancet ii, $124(1975)$.

19. Madeley, C. R., Cosgrove, B. P.: $28 \mathrm{~nm}$ particles in faeces in infantile gastroenteritis. Lancet $\mathrm{ii}, 451-452(1975)$.

20. Madeley, C. R., Cosgrove, B. P.: Calicivirus in man. Lancet i, 199-200 (1976).

21. MADELEY, C. R.: Comparison of the features of astroviruses and caliciviruses seen in samples of feces by electron microscopy. J. inf. Dis. 139, 519-523 (1979).

22. Mathan, M., Mathan, V. I., Swaminathan, S. P., Yesudoss, S., Baker, S. J.: Pleomorphic virus-like particles in human faeces. Lancet $i, 1068-1069(1975)$.

23. Mrdoleton, P. J., Szymansier, M. T., Petric, M.: Viruses associated with acute gastroenteritis in young children. Amer. J. Dis. Child. 131, 733-737 (1977).

24. Pocock, D. H.: Effect of sulphydryl reagents on the biological activities, polypeptide composition and morphology of haemagglutinating encephalomyelitis virus. J. gen. Virol. 40, 93-101 (1978).

25. Pollock, R. V. H., Carmachaen, L. E.: Canine viral enteritis. Mod. Vet. Pract. 60, 375-380 (1979).

26. SrEgL, G.: The Parvoviruses (Virology Monographs, Vol. 15), 109. Wien-New York: Springer 1976.

27. Strodgrass, D. R., Gray, E. W.: Detection and transmission of $30 \mathrm{~nm}$ virus particles (astroviruses) in faeces of lambs with diarrhoea. Arch. Virol. 55, 287-291 (1977).

28. Strodgrass, D. R., Angus, K. W., Gray, E. W., Menzies, J. D., Paul, G.: Pathogenesis of diarrhea caused by astrovirus infections in lambs. Arch. Virol. 60, $217-226(1979)$.

29. Spratet, H. C., Marks, M. I., Gomersalt, M., Gill, P., Pai, C. H. : Nosocomial infantile gastroenteritis associated with minirotavirus and calicivirus. J. Pediatr. 93, $922-926(1978)$.

30. Statr, E. L., Rromes, M. B., Whrre, R. G., Mebus, C. A. : Neonatal calf diarrhea: purification and electron microscopy of a coronavirus-like agent. Amer, J. vet. Res. 33, 1147-1156 (1972).

31. Trrafel, D. A. J., Alexander, D. J., Almemd, J. D., Cunnimghay, C. H., Easterday, B. C., Garwes, D. J., Hierholzer, J. C., Kaptuian, A., MacnaughTon, M. R., McIntosh, K. : Coronaviridae: Second report. Intervirology 10, 321 to $328(1978)$.

32. WOODE, G. N., BRLDGER, J. C.: Isolation of small viruses resembling astroviruses and calciviruses from acute enteritis of calves. J. med. Microbiol. 11, 441-452 (1978).

Author's address: F. P. WrLlisms, JR., Health Effects Research Laboratory, U.S. Environmental Protection Agency, 26 West St. Clair Street, Cincinnati, OH 45268, U.S.A. 